\title{
A pediatria social e as suas apostas reformistas
}

\section{Social pediatrics and its reformist proposals}

Maria de Lurdes Zanolli 1

Emerson Elias Merhy 2

\footnotetext{
1 Departamento de Pediatria, Facul dade de Ciências Médicas, Universi dade Estadual de Campinas.C. P. 6111, Cidade Universitária Zeferino Vaz, Campinas,SP 13083-970, Brasil. zanolli@fcm.unicamp.br

2 Departamento de Medicina Preventiva e Social,

Faculdade de Ciências Médicas, Universidade Estadual de Campinas. C. P. 6111 , Cidade Universi tári a Zeferino Vaz, Campinas, SP 13083-970, Brasil. emerhy@head.fcm.unicamp.br
}

\begin{abstract}
A bstract This article reflects on the constitution of Social Pediatrics in Brazil, vi ewing it as a movement for reform in children's health care invol ving teaching, services, and pediatric practice. The article includes a historical and bibliographical review of the Social Pediatrics' field and the provision of children's health care, analyzing its relations with movements for the reform of medical education and health careand its conceptual framework, including several authors' definitions and formulations on thetheme.

Key words Child Health; Pediatrics; Medical Care

Resumo Realiza-se, nesteartigo, uma reflexão sobrea constituição da pediatria social no Brasil, compreen dendo-a como um movimento de formação de propostas de reformas da atenção à saúde da criança, que contempla uma tripla proposta reformista: do ensino, do serviço e da prática pediátricos. O trabalho inclui uma recuperação hi stórica ebibliográfica do campo da pediatria social que é relativo ao cui dado com a criança e a forma de prestá-lo, analisando-o através de suas relações com os movimentos mais gerais de reforma do ensi no médi co e da aten ção à saúde. Tece,ain da, consi derações sobre seu arcabouço conceitual, com base nas definições e formulações sobre o tema apontadas por alguns autores.

Palavras-chave Saúdelnfantil; Pediatria; Assistência Médica
\end{abstract}


Introdução

No Brasil, a pediatria social é uma área da prática pediátrica que traz, na sua constituição, propostas reformistas. Aposta na tríplice reforma da prática pediátrica, da escola médica edo serviço de saúde, influenciada pel os movimentos políticos mais amplos da área da saúde verificados no país.

A pediatria social, como campo de práticas e saberes, começou a ser construída no Brasil no final da década de 60 e início de 70, junto com as propostas de reforma do ensino e da atenção médica influenciadas pelos movimentos de medicina integral, medicina preventiva, medicina comunitária e medi cina social. Posteriormente, na década de 80 , sofreu influência da reforma sanitária e da integração docente assistencial e, mais recentemente, nos anos 90 , da saúde coletiva.

O movimento da medicina social trouxe discussões sobre a medicina e a sociedade, situando as políticas de saúde como aquelas que visavam à produção e à reprodução das classes sociais nas distintas sociedades; repensou o conceito de saúde e o entendimento do processo de saúde/ doença; anal isou a constituição das ações e práticas de saúde como modelo tecno-assistencial; reconsiderou, com a incorporação das ciências sociais e humanas, a conformação do corpo biológico enquanto objeto da medicina (Arouca, 1975; Canguilhem, 1990; Donnangelo \& Pereira, 1976).

Influenciada por esses referenciais, a atenção à criança também foi relida no País, e desenvolveram-se várias experiências, todas tendo como obj etivo a reforma da prática pediátrica. A partici pação dos departamentos de pediatria e de medicina preventiva e social na reforma das escolas médicas e em programas comunitários constituíram um campo privilegiado, tanto para o questionamento, como para o desenvolvimento de novas práticas nos espaços assistenciais. Estruturaram-se, assim, o discurso e o campo de práticas da pediatria social.

Os discursos da pediatria social têm uma multiplicidade de origens e de fundamentos, que chegam muitas vezes a se contrapor. No entanto, todos confluem para a idéia de reformar $a$ atenção à criança.

O objetivo deste trabal ho é fazer uma reflexão sobre a constituição da pediatria social no Brasil, revendo as suas definições e proposições em articulação com as questões da assistência à criança e do ensino de pediatria. Procurar-seá delinear o contexto de seu surgimento e de estruturação da sua prática, por meio da análise das suas relações com os movimentos mais gerais de reforma do ensino médico e da atenção à saúde no País, tendo por referência diversas definições e formulações de alguns autores sobre o tema.

Para mel hor compreender a conformação adquirida pela pediatria social no Brasil, realizar-se-á uma breve revisão histórica e bibliográfica, tendo por objeto os temas do cuidado à criança e das formas de prestá-lo, procurando, desse modo, delinear seu arcabouço conceitual e sua articulação com a saúde coletiva brasileira.

\section{O cuidado à criança e a forma de prestá-lo}

A atitude para com a criança varia de acordo com a organização das diferentes sociedades, culturas e períodos. O código de Hamurábi dos babilônios, entre 2500 e 2000 a.C., tinha leis que protegiam os órfãos e abandonados. Entre os romanos, existia a venda, o abandono ou o infanticídio pelos mais diferentes motivos: sacrifícios religiosos, econômicos, equilíbrio entre sexos, malformações, ou por serem filhos ilegítimos ou de escravos. Os egípcios, os germanos e os judeus criavam todas as suas crianças. Desde a antigüidade, existem textos sobre proteção e cuidados em relação à alimentação, higiene, aprendizado e atividade física da infância. Hipócrates (462 a.C.) e os seus discípulos já ressaltavam as vantagens do aleitamento materno (Crespin, 1992).

As classes de idade da antigüidade pressupunham uma diferença e uma passagem (através da iniciação ou de uma educação) entre o mundo das crianças e o dos adultos. Para a civilização medieval esta diferença não existia. Assim que adquiria desembaraço físico, a criança era misturada aos adultos nos seus trabaIhos e jogos, passava de criancinha pequena a homem jovem. A modernidade retomou a preocupação com a educação. Inicial mente por parte de alguns juristas e eclesiásticos, depois, no final do século XVI e no XVII, por reformadores religiosos, cujas ordens foram se dedicando ao ensino de crianças e jovens. $O$ aspecto moral da religião sobrepôs-se aos aspectos sacro e teológico, resultando em uma verdadeira moral ização da sociedade (Ariès, 1986).

Até o século XVII, a criança era responsabilidade da família. O Estado e a caridade só a assistiam em caso de abandono. O mercantilismo trouxe a preocupação com o aumento na produção e com o fortalecimento dos exércitos, fazendo com que o Estado interviesse para alcançar um aumento populacional. A popula- 
ção passou a ser um conjunto de indivíduos que deveriam ser contabilizados em seu número, nascimento e morte. Mudou a forma de ver a criança e o papel da família. Com o capitalismo, pela necessidade de mão-de-obra tanto para a produção, como para o consumo, intensificou-se o interesse pela conservação da criança. Estatísticas mostraram a relação da mortalidade geral e infantil com as condições de higiene col etiva. O Estado começou a se preocupar com as questões sanitárias e com a saúde da população (Marques, 1982).

Constituiu-se um modelo racional e, depois, científico (com Pasteur e a puericultura) que fornecia as regras e normas para o relacionamento dos adultos com as crianças. Regras e normas que, institucionalizadas pela medicina e pela pedagogia, passaram a ser as únicas socialmente legítimas. A pedagogia, principalmente por intermédio de Rousseau (1992), enfatizou a primeira educação, colocando-a como responsabilidade das mães, que deveriam ter mais autoridade e preocupação com o cuidado dos filhos e da família. Esse novo sentimento de infância era o resultado de atitudes para que se mantivessem a inocência e a pureza da criança ("bom selvagem"), preservando-a da corrupção do meio (conservando-a), fortalecen do-a para que desenvolvesse seu caráter e sua razão, através de proteção e cuidados para o seu devir social adulto. Para Rousseau (1992: 40), "nascemos capazes de aprender, mas não sabendo nada, não conhecendo nada" (tábula rasa). A educação infantil, utilizando idéias de puericultura e de economia doméstica como forma de assegurar corretamente o seu futuro papel de cidadão, passou a ser de responsabilidade da mãe, da família e da escola. Todas as crianças eram consi deradas iguais, de acordo com um ideal abstrato moldado na criança burguesa (Boltanski, 1974).

Para abrigar a família nuclear moderna, as habitações compartimentaram-se e fecharamse para a rua, que passou a ser "o local para a produção e, quando esta o permi tisse, para o lazer" (Rivorêdo, 1995:74). Essas novas constituições dos espaços e componentes da família e da sociedade iniciaram-se no século XVIII, solidificaram-se no XIX e mantêm-se (pelo menos nos conceitos) até hoje (Rivorêdo, 1995). A partir do século XIX, os serviços de saúde passaram a ter o papel de garantir a reprodução da capacidade de trabal ho. A medicina passou a ser a mais importante aliada do Estado moderno para que essas modificações ocorressem: primeiro através da higi ene, depois por meio da Puericultura e, contemporaneamente, pela saúde materno-infantil.

\section{A puericultura}

Antes de 1880, os textos e publicações dirigidos às mulheres sobre como cuidar ou tratar de seus fil hos eram em tom coloquial e amigável. Com os trabal hos de Pasteur e o desenvolvimento da microbiologia, essas regras e saberes adquiriram valores científicos, passando a ter um tom doutoral, ampliando a jurisdição da medicina, que se apropriou do conhecimento de como criar crianças. As mudanças na sociedade e na família da época fez com que esses saberes se transformassem em dogmas indiscutíveis, aparecendo obras em forma de catecismo, dirigidas às mulheres do povo, partindo da suposição de uma total ignorância das leitoras, inculpando-as pelas más condições de saúde (Boltanski, 1974; Marques, 1982; Novaes, 1979; Orlandi, 1985). A pediatria constituía-se do encontro da puericultura com a clínica de crianças, associando o desenvolvimento e a especificação do corpo infantil, impregnando-se da doutrina de conservação da criança (Mendes, 1996).

Esse discurso com base na puericultura veio a ser incorporado em parte pela escola, pelo senso comum, pelos meios de comunicação, e manteve-se nos programas da Organização Mundial da Saúde (OMS), tanto no maternoinfantil, como em parte das ações básicas de saúde, nos proj etos de diminuição da mortalidade infantil, como os do Fundo das Nações Unidas para a Infância (UNICEF), e na busca da atenção integral à saúde da criança (Freire, 1991; Novaes, 1979).

\section{Saúde materno-infantil}

Nas duas primeiras décadas do século $X X$, com a aproximação entre a saúde da mãe e a da criança, originou-se a concepção do binômio mãe-filho, passando-se a falar da saúde materno-infantil. Daí se caminhou para o ideal de proteção à família e desta para a comunidade. A proteção da sociedade e do Estado, principalmente sobre a população carente, justificase pela multiplicidade de fatores sociais, econômicos e culturais desencadeantes dos problemas de saúde. Essa trajetória culminou, na década de 20 , na perspectiva médico-sanitária americana, com a educação para a saúde, que "procurava tornar o indivídu o um participante ativo e responsável, não apenas pela própria saúde, mas pela ausência da doença na sociedade" (M arques, 1982:5). A ação sanitária deslocou-se da polícia médica para a educação sanitária. O discurso da puericultura, fundamen- 
tado no pedagógico, no psicológico e no higiênico, adquiriu um caráter mais científico e foi perdendo o seu tom moralizador e coercitivo, transformando-se em educativo (Marques, 1982; Novaes, 1979).

Após a Segunda Guerra Mundial, desenvolveu-se uma proposta de proteção à saúde materno-infantil planejada, instrumentalizada em programas e normas específicos, que se estenderia principalmente aos países subdesenvolvidos, por intermédio das agências internacionais de saúde (Marques, 1982).

\section{A tenção integral à saúde da criança}

Nas décadas de 50 e 60, sob a influência da teoria desenvolvimentista, que relacionava desenvolvimento econômico com melhoria de vida e esta com a saúde, colocando o planejamento como seu instrumento, intensificaram-se as propostas das agências internacionais e desenvolveram-se modelos que homogeneizavam os determinantes dos principais problemas de saúde e as suas formas de intervenção (Braga \& Paula, 1986).

O movimento da medicina preventiva e, posteriormente, a medicina comunitária apresentaram uma proposta de atenção integral racionalizadora e hierarquizante, através de uma rede de serviços ambulatoriais com alcance completo, centralizada em um hospital (se possível relacionado a uma escola médica), prevendo a participação da população tanto na detecção de problemas na comunidade, quanto na execução das ações de saúde. Partia dos conceitos de multicausalidade e de enfoque de risco, reforçando-se a atenção materno-infantil. A prática da puericultura perdeu espaço para a doen ça; as ações de saúde foram sistematizadas em normas de atendimento para os atos médicos e para os procedimentos não médicos, priorizando determinadas populações ou patologias (Freire, 1991; Marques, 1982).

As políticas posteriores do UNICEF e da OMS priorizaram o combate à mortalidade infantil, incorporando no seu discurso a determinação social do processo saúde-doença e a necessidade de ampliação da assistência até a adolescência. Suas ações, contudo, dirigiramse basicamente para: o combate da doença diarréica (através da terapia de reidratação oral), a monitorização do crescimento e do desenvolvimento, o estímulo ao aleitamento materno, o cuidado com a alimentação e a vacinação (Freire, 1991).
A tenção à criança no Brasil e limitações dessa ação

No Brasil, o cuidado com a criança teve, até o início do século XX, um caráter filantrópico, com a veiculação das propostas da puericultura e com o desenvolvimento não só de instituições de assistência e proteção à infância, como também de institutos profissionalizantes, destinados às crianças pobres, doentes e abandonadas (Novaes, 1979).

A partir de 1910, em resposta às reivindicações operárias, o Estado estabeleceu as primeiras leis sociais (regulamentação do trabal ho da mulher grávida, do menor etc.). Nas décadas de 20 e 30, foram organizados os serviços materno-infantis (incorporando a puericultura), através de estruturas verticalizadas, junto com o início da política previdenciária. O Departamento Nacional da Criança surgiu em 1940, tornando-se o responsável pela criação e orientação técnica dos serviços de prestação de assistência à criança, através dos postos de puericultura. Nos anos 50 e 60, a preocupação com a mortalidade infantil e com a expansão da rede de serviços levou a um aumento significativo desses postos especializados, duplicando o atendimento às crianças, feito também pelas unidades polivalentes, ligadas a departamentos e orientações técnicas distintas, que só se integraram após 1969 (Tanaka, 1982).

Na década de 70, sob a influência dos movimentos da medicina preventiva e comunitária, reafirmou-se a importância da saúde maternoinfantil, mas as ações propostas foram pouco implementadas. O Programa de Atenção à Criança, elaborado em 1976 como um dos programas de assistência médico-sanitária, resultou em um atendimento público racionalizador e burocrático, mesmo no Estado de São Paulo onde estava apoiado nas diretrizes da reforma administrativa da Secretaria de Saúde, e trouxe melhorias (Albuquerque \& Ribeiro, 1979; Tanaka, 1982).

O Programa das Ações Integradas de Saúde (AIS), criado em 1983, foi o que restou da proposta do Programa Nacional de Serviços Básicos de Saúde (Prev-Saúde) de 1980. Tinha como objetivo a universalização dos cuidados primários de saúde em todo o Brasil, com racionalização de recursos, introduzindo de fato o planejamento em saúde. Foi influenciado pela conferência de Alma-Ata, pelo fortalecimento dos movimentos sociais, pelas conferências nacionais de saúde e por instituições criadas nas décadas de 70 e 80 (CEBES - Centro Brasileiro de Estudos de Saúde; ABRASCO - Associação Brasileira de Pós-Graduação em Saúde Co- 
letiva), que, posteriormente, originaram o movimento da reforma sanitária (Mendes, 1993). O programa das AIS incluía o Programa de Atenção Integral da Criança e do Adolescente. No Estado de São Paulo, além das ações básicas de saúde (monitorização do crescimento, aleitamento materno, controle de doenças diarréicas, controle de doenças respiratórias agudas e controle das doenças nutricionais), este programa compreendia a atenção à saúde de grupos etários em especial (recém-nascidos, lactentes e pré-escolares, escolares e adolescentes), a saúde mental e a suplementação al imentar.

Com as AIS e, depois, com o Sistema Unificado e Descentralizado de Saúde (SUDS), em 1987, ocorreram avanços no planejamento e gerenciamento dos serviços, ampliação das ações, descentralização de recursos da saúde nos planos estaduais e municipais. Mas essa descentralização foi limitada pela dependência financeira e política dos municípios em relação às outras esferas. Quanto às ações, foi mantido o atendimento segmentado, com princípios programáticos rígidos, com medicação excessiva de parte da clientela, dificultando o acesso da população na sua universalidade. Mesmo com o Sistema Único de Saúde (SUS), essas dificuldades se mantiveram, e a efetiva implantação das ações continua na dependência do modo pelo qual os diversos níveis do sistema se organizam e se relacionam e da capacidade de organização da população (Campos, 1992; Merhy, 1989). A proposta do Programa de Atenção Integral da Criança e do Adolescente manteve-se basicamente a mesma, mas a maioria dos serviços adquiriu características de pronto-atendimento, dificultando a sua execução, não atendendo às necessidades de saúde da população e não garantindo a integralidade das ações (Tanaka \& Rosenburg, 1990).

Das críticas às possibilidades de atuação na atenção à criança no Brasil

Além de autores como Arouca (1975), Donnangelo \& Pereira (1976), Rosen (1979), Foucault (1986), Garcia (1983) e Canguilhem (1990), do movimento da medicina social, outros, como Ariès (1986), com as análises que fez sobre as sociedades tradicionais e sobre o lugar da criança e da família nas sociedades industriais; Donzelot (1986), com o livro A Polícia das Famílias; Boltanski (1974), com sua análise da puericultura como forma de regular a vida das pessoas e da sociedade, trouxeram também contribuições essenciais para repensar o cuidado com a criança.
Os questionamentos que daí surgiram passaram a se dirigir para a forma de pensar, ensinar e pesquisar a pediatria e a puericultura, bem como de efetivar a atenção à criança. Realizaram-se estu dos sobre a história e a constituição da puericultura e da pediatria no Brasil, análises de projetos alternativos de atenção à saúde da criança e trabalhos sobre as formas do cuidado com a criança e as instituições por esta responsáveis. Todos esses estudos e questionamentos reafirmavam e ao mesmo tempo tentavam estruturar a tripla intenção de reforma do serviço, do ensino e da prática pediátrica.

Marques (1976) desenvolveu no Município de Paulínia (São Paulo), entre 1974 e 1976, uma das primeiras experiências com o Programa de Atenção Materno-Infantil (PAMI), incluído no Projeto de Saúde da Comunidade da Faculdade de Ciências Médicas da Universidade Estadual de Campinas (UNICAMP). O PAMI de Paulínia partiu do antigo programa e serviço de puericultura e, com uma equipe multiprofissional, ampliou sua faixa de atendimento, introduziu a noção de risco de adoecer e morrer, fazendo, além do atendimento individual, grupos de mães e visitas domiciliares. Tinha como princípios: compromisso social em relação aos interesses e necessi dades da comunidade; busca de síntese entre o saber médico e o saber popular, com base na qual se concretizavam as ações de saúde; caráter explicativo e não autoritário das atividades de saúde em todas as fases do atendimento, levando profissionais e comunidade a se apropriarem dos saberes populares e médicos respectivamente. Transformou a atuação dos profissionais da saúde em instrumento educativo, deixando de constituir um fim em si mesmo. Seu objetivo era o de recolocar a puericultura "diante da visão de mundo dos seres humanos concretos a quese dirige" (Marques, 1976:30).

Em sua análise do trabalho do PAMI, estudando de um período de 17 meses, Marques (1976) verificou que a captação da clientela foi mais precoce e mantida, e que houve diminuição dos óbitos e das formas graves de desnutrição nos primeiros seis meses de vida; contudo, permaneceram ainda elevadas a morbidade, a mortalidade e a desnutrição leve e moderada. O estudo revelou, ainda, que a convivência entre a equipe e a população havia sido suficiente para a transmissão de conhecimentos mútuos, importante em face da situação de doença, e para consolidar uma postura mais crítica diante do próprio setor da saúde, tanto por parte da população como da equipe, levando à compreensão das limitações do serviço (de puericultura) na resolução daqueles problemas. 
Novaes (1979) estudou as condições históricas do aparecimento da puericultura na França e no Brasil, o significado do discurso da puericultura nas diferentes conjunturas (política, econômica e social) e as transformações pelas quais ele foi passando, os locais em que se manifestou e os fatores que o influenciaram.

Sucupira (1981:16) investigou a relação médico-paciente, entendida por ela como “uma forma concreta de relação social que apresenta peculiaridades próprias na medida em que se realiza em insti tuições específi cas e émediatizada por um saber específico portado por apenas um dos elementos". A pesquisa foi realizada em centro de saúde, em unidade própria do INAMPS (Instituto Nacional de Assistência Médica da Previdência Social) e em serviço de medicina de grupo, mediante observação direta, observação participante na sala de espera e entrevistas após o atendimento, buscando compreender o processo de consumo dos serviços pela população.

Alguns autores empreenderam análises e avaliações de diferentes aspectos de serviços de atenção à criança com metodologias quantitativas e qualitativas. Albuquerque \& Ribeiro (1979) analisaram o Programa de Assistência à Criança desenvolvido em um centro de saúde estadual e em um municipal, investigando o que representou para as respectivas populações usuárias, o modo de articulação com as suas condições materiais de existência e a sua importância como assistência médica propriamente dita. Utilizaram dados de produção e qualidade dos serviços, além de realizar entrevistas e observação direta.

Tanaka (1982) analisou o Programa de Assi stência à Criança da Secretaria de Estado da Saúde de São Paulo, no período de 1977 a 1980, na região da Grande São Paulo e no estado como um todo, através dos seus indicadores de avaliação e produção e da análise da qualidade das atividades programadas, utilizando-se de auditoria de prontuários e observação direta. Em 1988, Tanaka \& Rosenburg (1990), por meio de estudo da clientela usuária, analisaram a utilização de um posto de assistência médica e de um pronto-atendimento de uma mesma região, visando também verificar a questão da atenção integral à saúde.

Marques (1982) abordou a questão populacional internacional e as doutrinas e práticas sanitárias voltadas para a saúde materno-infantil. Trouxe considerações sobre o movimento pelo bem-estar da maternidade e da infância e crítica ao discurso médico-demográfico, colocando, posteriormente, a questão da atenção materno-infantil como prioridade política.
Freire (1991), ao pesquisar o discurso da OMS, percebeu que a puericultura, com seu discurso homogeneizador calcado na pedagogia, está presente de forma marcante como conteúdo nos informes técnicos da OMS da área de saúde materno-infantil, priorizando a educação e a racional ização de ações e condutas e propondo soluções de ordem médica para a resolução de problemas cuja causa é principalmente social.

Outras pesquisas e reflexões abordando discussões de temas e preocupações com a criança foram realizadas, buscando entendêlas além das suas determinações biológicas, tentando compreendê-las nas suas amplitudes culturais, sociais e econômicas (Castro, 1980; Minayo, 1987, 1995; Monteiro et al., 1989; Moysés \& Lima, 1983).

Todos esses estudos contribuem para a formação de um corpo conceitual e de uma proposta de intervenção para a pediatria social no Brasil, que se utiliza também das definições e objetivos apontados pelos próprios pediatras comprometidos com a idéia de uma pediatria social.

Os pediatras em busca das próprias definições e delimitações para um novo campo de práticas

Marcondes (1973) situou a pediatria social como um dos cinco setores da pediatria (preventiva ou puericultura, clínica, cirúrgica, neonatal e social), que devem ser intercomunicantes para cumprir a doutrina da área: propiciar a assistência integral à criança. Para ele, a pediatria preventiva e a social são as que mais traduzem os aspectos doutrinários da pediatria.

Segundo Marcondes, os objetivos da pediatria social são o estudo e a assistência globais da criança através do conhecimento dos fatores ambientais, psicológicos, econômicos, sociais e culturais, que incidem sobre o menor e sua família e que podem predispô-lo a uma determinada doença. A pediatria social é um trabal ho a ser real izado em equipe. Deve preocupar-se com o universo de crianças (e não prender-se a esta ou aquela) da comunidade; lidar com o ambiente (comunidade) em que vivem; deve, também, conhecer e se entrosar com os recursos da comunidade, tanto assistenciais, como sociais e de infra-estrutura, públicos, filantrópicos ou privados. Tem como metas diminuir o risco de mortalidade infantil e a morbidade da criança; proporcionar medidas para a promoção de sua saúde, "a fim derealizar seu desenvolvimento integral e culminar em um 
adulto normal, feliz e socialmenteútil" (Marcondes, 1973:23). Para esse autor, tal enfoque deve ser prioritário principalmente nos países subdesenvolvidos, pelo predomínio de população jovem e pelos seus problemas. O pediatra social necessita, além dos "predicados exi gidos para ser simplesmente um pediatra, características especiais depersonali dade, bem como treinamento em ciências correlatas básicas (epidemiologi a,antropologi a cul tural,demografia e outras)" (Marcondes, 1973:22).

Marques (1986) também considera a pediatria social (ou "Saúde Materno-Infantil") como um dos setores básicos da pediatria, ao lado da pediatria clínica ou curativa e da pediatria preventiva ou puericultura. Ressalta que a pediatria é uma só e atribui essa divisão a razões metodológicas ou ao fato de que "ela infelizmente é exercida de maneiras diferentes diantedas diferentes classes sociais" (Marques, 1986:2). Observa que a importância da medicina social e da pediatria social originou-se, após a Segunda Guerra Mundial, da tomada de consciência das desigualdades sociais e nacionais e da necessidade de recorrer a sistemas coletivos em benefício dos indivíduos ou das coletividades economicamente deficientes, que resultaram em formas coletivas de assistência médica.

Marques aponta dois atributos sem os quais a pediatria social não deve ser considerada como tal: racionalidade e coletivização. A pediatria social realiza ações tanto de prevenção, quanto de cura; atua como pediatria preventiva e clínica; "é a Pediatria Integrada em seu mais amplo sentido" (Marques, 1986:3). Seus objetivos são a previsão e a solução dos problemas da infância, preocupando-se também com as questões maternas, por isso, e nessas condições, o autor a considera sinônimo de assistência ou atenção materno-infantil. A pediatria social ("a medicina social da infância") deve estar presente junto aos demais setores da organização sanitária e das estruturas de saúde pública, pois o seu estudo compreende também os fatores econômicos, demográficos, sociais, culturais, sanitários, políticos e administrativos, que influenciam a situação de saúde das populações.

Em suma, para Marques (1986:8), a pediatria social “deve objetivar o mais completo bemestar social detodas as crianças emães, integradas em uma sociedade justa efeliz. Para tanto, é indispensável o mais alto grau de consciência social e política, no permanente empenho de empregar, em seu proveito, tudo o que debom a inteligência humana for capaz". O autor ressalta que não deve haver nenhuma forma de discriminação entre as diversas camadas das po- pulações, além de enfatizar que as equipes e os órgãos de pediatria social, "na amplidão de suas possi bilidades e de sua doutrina, devem se empenhar a fundo para al cançar estes objetivos,empregando esforços, utilizando recursos, convencendo as pessoas e influindo nas modificações dos concei tos, das leis e demais posturas legais" (Marques, 1986:8).

Para Orlandi (1985:13), a partir do surgimento da medicina social, "com o desenvolvimento científico do século XIX, e um con hecimento melhor da criança, desuas necessidades e de sua patologia, era natural que surgisse um ramo novo: a Pediatria Social", a qual considera a criança um ser social, estando suas patologias, em grande parte, ligadas aos fenômenos sócio-econômicos. Para ele, com a crise estrutural da medicina e o movimento da medicina social nas décadas de 60 e 70, ocorreram novos estudos sobre as relações entre saúde e sociedade. Foram desencadeados questionamentos sobre a medicina e suas instituições, resultando em uma profunda revisão crítica destas e de suas pesquisas, que também se esten deram às relações entre saúde infantil e sociedade. A criança, a infância e as questões relativas a elas devem ser estudadas, compreendidas e consideradas, respeitando-se as diferentes populações infantis de acordo com a sua classe social e social ização. Não devem ser vistas como "coisa" ou problema: "as crianças não são um problema brasi lei ro; os problemas é que o são para as crianças brasileiras"' (Orlandi, 1985:15).

Partindo dessa perspectiva, Orlandi analisa, historicamente, o significado da infância e sua inserção nas famílias, nas diferentes socie dades e classes sociais, na pediatria, na puericultura e na educação (puericultura como primeira educação, educação pré-escolar e fracasso escolar). Aborda também questões como a medicação da sociedade, a mortalidade infantil, o aleitamento materno e o controle da natalidade, principalmente através da puericultura e, posteriormente, da saúde maternoinfantil, ressal tando seu sentido ideológico. Para ele, pediatra e puericultor confundem-se na prática. Quem trata da criança doente é o orientador dos cuidados dela quando sadia. $\mathrm{O}$ puericultor e o seu ato têm um papel bio-político-social. "Sempreque o puericultor deixa de fazer política, encoberto pela capa da pseudoneutralidade da puericultura, está fazendo uma puericultura das classes dominantes e não uma puericultura dos desamparados, uma puericultura consciente", e "uma puericultura retrógrada, reacionária, formará por certo família, pais ecrianças submissos, dóceis,incapazes de participar edereivindicar" (Orlandi 1985:21). 
No prefácio do livro de texto Social Paediatrics, Lindström \& Spencer (1995) afirmam que a pediatria social está preocupada com as influências sociais, políticas, ambientais e familia res sobre a saúde da criança, nos planos populacional e individual. Ela não é separada da pediatria tradicional, mas se incumbe de seus contextos social e familiar. Permite aos profissionais da saúde da criança olhar além do processo da doença na criança, esta considerada individualmente, e dirige-se aos principais determinantes sociais da saúde-doença na infância.

Manciaux (1995) situa a pediatria social como a parte da saúde pública que diz respeito à criança e não como um ramo da pediatria, uma vez que lida com a saúde de determinados grupos de toda a população e representa o ponto de encontro de várias disciplinas que contribuem, interativamente, para a saúde desses grupos como um todo. Também se interessa pelos aspectos psicossociais da saúde e da doença da criança individualmente, tendo, portanto, uma dimensão populacional e uma abordagem global.

Para Manciaux, na Europa, não há consenso sobre o conceito de pediatria social, pois alguns autores trazem definições muito específicas ou parciais. Argumenta que a abordagem mais apropriada deve concentrá-la no campo das atividades pertencentes à saúde, cuidado e bem-estar da criança. Considera também que a pediatria social tem assegurado, em países europeus e no plano internacional, contribuições cruciais para o desenvolvimento e o conhecimento da criança e de atividades voltadas ao bem-estar desta. Citando Robert Debré: "Pediatria Social não éuma especialidade, ela é um estado de espírito" (Debré, 1963, apud Manciaux, 1995:3), Manciaux afirma que ela é, de fato, o ponto de encontro e a fertilização de várias disciplinas. Tem ligações com a clínica pediátrica, obstetrícia social, perinatologia, genética, sociologia, antropologia, psicologia, pedagogia, biologia, direito, economia, saúde pública e epidemiologia. Concluindo que a pediatria social se situa no ponto de encontro da epidemiologia e da estatística, das ciências clínicas e das ciências humanas, também sendo relevante para o desenvolvimento psicossocial, o autor pensa que, a exemplo da geriatria social, que evoluiu para a gerontologia, talvez também a pediatria social possa vir a ser uma pedontology. Segundo Manciaux, as interligações entre pediatria social, saúde da família, saúde comunitária, saúde pública e pediatria do desenvolvimento são sutis, e o conceito de saúde global da criança é, provavelmente, o caminho mais apropriado para reconciliar essas discipli- nas com a pediatria social e nos dar uma visão clara do assunto.

De acordo com Bellizzi (1989), a alta mortalidade infantil, as doenças, os problemas e desajustes sociais são desafios políticos e sociais e não apenas técnicos. Ressalta o cuidado de não medicarmos problemas sociais. O médico deve unir-se aos outros profissionais (cientistas sociais, economistas, físicos, engenheiros etc.) a fim de usar suas figuras de impacto e ações cumulativas para um trabalho norteado de investimento social. O autor destaca a importância da comuni cação de massa e da mobilização popular para ajudar na solução desses problemas. Para ele, os “investimentos aplicados no povo em educação para a saúde têm o mais imediato, rentável eseguro retorno decapital" (Bellizzi, 1989:3). Especifica algumas medidas e ações já consagradas, que, se aplicadas e reforçadas, resolveriam parte dos problemas: imunização, aleitamento materno, terapia de reidratação oral e escolaridade materna.

Segundo Kasse-Acta (1988), a pediatria social trata da criança sadia ou doente considerando o grupo do qual ela faz parte e o meio no qual se desenvolve. Nos dois aspectos, profundamente ligados, da pediatria - pediatria clínica (que estuda as enfermidades) e pediatria preventiva ou puericultura (que se preocupa com a conservação da saúde e com a prevenção das doenças) - , tudo o que diz respeito à influência do meio e da sociedade sobre a criança ou o papel desta no meio e na sociedade é do domínio da pediatria social. Ela está na confluência de terrenos próprios da pediatria e de outras ciências relacionadas com o homem e a sociedade, nas quais deve apoiar-se para ampliar suas perspectivas e investigações. Para o autor, o pediatra deve estar englobado na proteção social da criança, deve incorporar-se ao terreno da pediatria social, não pode estar alheio aos problemas sociais, seja como profissional, seja como cidadão; deve encarar esses problemas integrando-se ativamente às instituições voluntárias ou assessorando-as “como líder indiscutible que es dentro del âmbito medicosocial" (Kasse-Acta, 1988:815-816). O autor destaca os aspectos col etivos da pediatria social, quando esta se preocupa com as doenças e com a prevenção ou puericultura; os aspectos individuais da criança doente e da prevenção em relação à proteção; os principais problemas sociais: nutrição, higiene, inadaptação, abandono e comunidades infantis. Ressalta que a pesquisa e o ensino da pediatria social devem ser valorizados pelas escolas médicas.

Mendes (1996), em trabalho sobre a prática pediátrica nos centros de saúde, refere que a 
pediatria social costuma ser designada "como a área em que se situam as práticas deensino e pesquisa voltadas ao campo da Saúde Coletiva referentes à criança, assi m como a área em que seconcentram as ativi dades de ensino dePediatria nos centros de saú de para alunos e resi dentes". Consi dera difícil "precisar os saberes e práticas que constituem a especi fi ci dade da Pediatria Social, anteriormente à prática de ensino nos Centros de Saúde" (Mendes, 1996:3). Uma possibilidade, segundo este autor, é considerar como pediatria social o que antes era puericultura e que seria atualizada posteriormente, com as contribuições das reformas médicas e do ensino médico a partir da década de 70 , as quais tiveram como resultado a constituição dos departamentos de medicina preventiva e social. Estes, em conjunto com os departamentos de pediatria, foram os principais responsáveis pela implantação de projetos de medicina comunitária. Nesse novo contexto, o ensino da puericultura passaria a incorporar saberes e práticas de outras áreas, como saúde pública, medicina preventiva, e integraria a medicina comunitária. Outra possibilidade, porém, segundo Mendes, é considerar que a especificidade da pediatria social decorre da necessidade de os departamentos de pediatria desenvolverem suas especialidades, agrupando em uma mesma área (ainda inespecífica) “temas de Puericultura eda grandeárea de Pediatria Geral, liberando corações e mentes para o aprofundamento nas pesquisas e atividades das especial i dades pedi átri cas e no desenvol vi mento tecnológi co aplicado à clínica Pediátrica" (Mendes, 1996:4).

\section{Conclusão}

Ao examinar os vários conceitos e objetivos apresentados por diversos autores a respeito da pediatria social, verifica-se que esta sofre a influência de uma multiplicidade de disciplinase áreas. As visões dos autores variam muito e diversas vezes chegam a se contrapor; enquanto al guns adotam defin ições amplas para a pediatria social, outros são muito específicos ou parciais, indo da condição de disciplina a estado de espírito, de especialidade pediátrica a ramo da saúde pública. Todos esses discursos, ainda que às vezes opostos, entretanto, adotam a perspectiva de reformar a pediatria e sua clínica, por considerarem a prática pediátrica incompleta e fragmentada, ficando a pediatria, portanto, sujeita a uma ação reformista. A pediatria social aparece, assim, nesses discursos, como uma nova forma ou um modo mais completo de ver ou prestar o cuidado ou $a$ atenção à saúde da criança.

A pediatria social vai se estruturar como área de atuação da prática pediátrica, valendose da puericultura, da saúde materno-infantil (que relê a puericultura e incorpora conceitos da epidemiologia e da demografia), da epidemiologia, da saúde pública, da medicina preventiva, da medicina social e da clínica pediátrica.

A pediatria social, para interpretar a situação da criança e seus problemas, passa a incorporar, da medicina social, a noção da determinação social do processo saúde-doença, que muito contribuiria para colocá-la como proposta reformadora da pediatria. Considera-se, entretanto, que na sua prática, até hoje, a pediatria social continua sendo uma prática clínica, de modo predominante, mais do que uma nova disciplina ou modalidade de medicina social, apoiando suas ações, principalmente, nas disciplinas da clínica pediátrica e da saúde pública, na epidemiologia e em estraté gias da medicina preventiva. Constitui-se, na realidade, em uma área de práticas e ensino da pediatria voltada para a atenção integral da saúde da criança, vista de uma ótica individual e, apenas esporadicamente, como uma proposta de ação coletiva.

As práticas da pediatria social identificamna, por conseguinte, mais com a medicina pre ventiva e comunitária do que com a social. A contribuição desta úl tima aparece mais na análise crítica das circunstâncias sociais que influenciam a saúde da criança. Argumenta-se que a pediatria social talvez seja a área da medicina na qual a medicina preventiva tenha encontrado a sua maior aliada, apesar das insuficiências desta última assinaladas por Arouca (1975).

Na sua tríplice aposta reformista, em relação ao ensino médico, a pediatria social alcançou descentralizar pequena parte das atividades de ensino para os centros de saúde e levantar discussões teóricas na graduação ou na residência em pediatria, porém com carga horária no máximo igual à das áreas de internação ou ambulatórios especializados.

A prática realizada nos centros de saúde, todavia, raramente é voltada para os temas coletivos, centrando-se no atendimento individual, no qual busca pela integralidade das ações. Esta integralidade é, porém, difícil de ser obtida nas atuais condições do sistema de saúde no Brasil. Existem barreiras ao acesso, e a integração entre os diferentes níveis de atendimento complica-se, não se processa de modo adequado. Considerando-se que, nem mes- 
mo no interior da unidade de saúde as ações se integram, a proposta de reforma do serviço de atenção à criança da pediatria social contribuiu apenas para o aumento da oferta de atendimento à criança e ao adolescente, dentro da tendência mais geral de evolução do sistema de saúde como um todo.

Diversos projetos alternativos têm sido propostos, geralmente por meio de experiências municipais e algumas integradas ao ensino médico. Tais propostas conseguem mostrar que são reais as possibilidades de atuação dentro de uma rede ou distrito de saúde e sinalizam uma atenção à saúde da criança e do adolescente que, afirmando a saúde como um direito humano, consegue assegurar o acesso aos diferentes níveis do sistema, visando à integralidade das ações de saúde e atos médi cos responsáveis.

Projetos e discursos altamente compromissados com as reformas do ensino médico e da saúde estão dedicados à implantação do SUS e da formação e educação continuada de profissionais que atuem ou venham a atuar nele, em qual quer dos seus níveis. Contudo, tais projetos esbarraram (e ainda esbarram) na sua implantação ou implementação, em dificuldades financeiras, políticas e organizacionais. Muitas dessas propostas, entretanto, na busca de respostas imediatistas e racionalizadoras, de controle de custos e, até mesmo, visando a aspectos comerciais, esquecem-se de que o maior lucro na saúde é representado pela própria saúde ou pela vida. Diversos projetos de pediatria social continuam centrando as ações no aten dimento médico individual, tornando-se apenas um pronto-atendimento que resolve, às vezes, o quadro agudo, sem, no entanto, maior repercussão no sistema. Ou, ainda, ao definirem a clientel a pelo risco de adoecer ou morrer, submetem-na também a programas de saúde centrados na doença e no atendimento médico individual, que, além de não atenderem as necessidades sociais e de saúde, dificultam o acesso da população a eles ou excluem parcela importante desta.
Apesar da ênfase, no discurso, ao direito à saúde e à determinação social no processo saúde-doença, principalmente para a população destituída, a abordagem continua centrada na doença. E, nos mesmos discursos, crianças e adolescentes continuam a ser encarados como devir ("os futuros ci dadãos", "nossos adultos de amanhã", "o futuro da nação"...). Ou seja, os serviços de saúde e também a atenção à saúde da criança e do adolescente continuam tendo, como missão principal, a garantia da reprodução da capacidade de trabalho na sociedade.

Nas escolas médicas, as tentativas de reformulação curricular acabam sendo superficiais, muitas vezes voltando-se apenas ao atendimento do mercado de trabalho. A dificuldade talvez esteja na contradição da própria instituição docente entre seus propósitos de mudança do ensino e sua persistência para conservar-se inalterada.

Em síntese, a pediatria social limita-se ao campo da pediatria, embora trazendo conhecimentos multirreferenciados, que vão enriquecê-la, aumentando a sua capacidade analítica e explicativa. Contudo, na qualidade de proposta de atuação, ao colocar-se como reformadora de toda a pediatria, perde especificidade e, em sua prática, realiza basicamente ações clínicas individuais, distanciando-se das estratégi as adquiridas ou possíveis de serem desenvolvidas com o enriquecimento que ela própria trouxe. Isto é, apesar de a pediatria social ampliar a competência da pediatria com novos saberes, no seu "fazer" não os incorpora, e, assim, perde-se em sua proposta reformista.

Com base nessas reflexões, considera-se que o principal desafio na atualidade, para a pediatria social, é como atuar na implantação efetiva do SUS. Assim sendo, ela deverá indagar se deve continuar isolada, insistindo nas suas apostas reformistas da pediatria, ou se deverá buscar o seu "fazer", reafirmando sua competência, suas possibilidades e seus limites, valendo-se de outras disciplinas e áreas e atuando de forma integrada a elas. 
Referências

ALBU QUERQUE, J. A. G. \& RIBEIRO, A. E., 1979. Da Assistência à Disciplina: O Programa de Saúde Comunitária. Relatório do Projeto Relações Institucionais em Agências de Saúde. São Paulo: Departamento de Ciências Sociais, Faculdade de Filosofia, Letras e Ciências Humanas, Universidade de São Paulo.

ARIĖS, P., 1986. História Social da Criança e da Família. 2a Ed. Rio de Janeiro: Editora Guanabara.

AROUCA, A. S. S., 1975. O Dilema Preventivista: Contribuição para a Compreensão e Crítica da Medicina Preventiva. Tese de Doutorado, Campinas: Faculdade de Ciências Médicas, Universidade Estadual de Campinas.

BELLIZZI, D., 1989. Pediatria social. Clínica Pediátrica, 13:3-6.

BOLTANSKI, L., 1974. Puericultura y Moral de Classe. Barcelona: Editorial Laia.

BRAGA, J. C. S. \& PAULA, S. G., 1986. Saú de e Previdência: Estudos de Política Social. 2a Ed. São Paulo: Editora Hucitec.

CAMPOS, G. W. S., 1992. Reforma da Reforma: Repensando a Saúde São Paulo: Editora Hucitec.

CANGUILHEM, G., 1990. O Normal eo Patológico. Rio de Janeiro: Forense Universitária.

CASTRO, J., 1980. Geografia da Fome- O Dilema Brasileiro: Pão ou Aço. 10a Ed. Rio de Janeiro: Antares/Achiamé.

CRESPIN, J., 1992. Puericultura: Ciência, Artee Amor. São Paulo: BYK.

DONNANGELO, M. C. F. \& PEREIRA, L., 1976. Saúdee Sociedade São Paulo: Livraria Duas Cidades.

DONZELOT, J., 1986. A Polícia dasFamílias. 2aa Ed. Rio de Janeiro: Graal.

FOU CAULT, M., 1986. Microfísica do Poder. Rio de Janeiro: Graal.

FREIRE, M. M. L., 1991. Vidas Desperdiçadas: A Puericultura no Discurso da OMS. Dissertação de Mestrado, Rio de Janeiro: Instituto Fernandes Figueira, Fundação Oswaldo Cruz.

GARCIA, J. C., 1983. Medicina e sociedade: As correntes de pensamento no campo da saúde. In: Medicina Social: Aspectos Históricos e Teóricos (E. D. Nunes, org.), pp. 95-132, São Paulo: Global Editora.

KASSE-ACTA, E., 1988. Perspectivas de la pediatria social. Revista Cubana de Pediatria, 60:813-825.

LINDSTRÖM , B. \& SPENCER, N., 1995. Social Paediatrics. New York: Oxford University Press.

MANCIAUX, M., 1995. What is Social Paediatrics and where does it come from? In: Social Paediatrics. (B. Lindström \& N. Spencer, ed.), pp. 3-11, New York: Oxford University Press.

MARCONDES, E., 1973. Pediatria: Doutrina e Ação. São Paulo: Sarvier.

MARQUES, A. N., 1986. Conceitos e objetivos da pediatria social. In: Pediatria Social: Teoria e Prática. (A. N. Marques, org.), pp. 1-9, Rio de Janeiro: Cultura Médica Ltda.

MARQUES, M. B., 1976. Análise das Limitações ePossibilidades de Atuação em um Serviço dePuericultura. Tese de Doutorado, Campinas: Faculdade de Ciências Médicas, Universidade Estadual de Campinas.
MARQUES, M. B., 1982. A Questão Populacional Internacional eas Doutrinas e Práticas Sanitárias Voltadas para a Saúde Materno-Infantil. Rio de Janeiro: Escola Nacional de Saúde Pública, Fundação Oswaldo Cruz. (mimeo.)

MENDES, E. V., 1993. Distrito Sanitário: O Processo Social de Mudança das Práti cas Sanitárias do Sistema Único deSaúde. São Paulo: Editora Hucitec/ Rio de Janeiro: ABRASCO.

MENDES, R. T., 1996. Trabal ho eDoutrina: Os Caminhos da Prática Pediátrica nos Centros deSaúde. Tese de Doutorado, Campinas: Faculdade de Ciências Médicas, Universidade Estadual de Campinas

MERHY, E. E., 1989. Brasil pós-64: Financiamento e modelos dos serviços. In: Planejamento Sem Normas (G. W. S. Campos, E. E. Merhy \& E. D. Nunes, org.), pp. 61-122, São Paulo: Editora Hucitec.

MINAYO, M. C. S., 1987. Raízes da Fome. 3a Ed. Petrópolis: Editora Vozes.

MINAYO, M. C. S., 1995. Os Muitos Brasis: Saúde e População na Década de 80. São Paulo: Editora Hucitec/Rio de Janeiro: ABRASCO.

MONTEIRO, C. A.; FREITAS, I. C. M. \& BARATHO, R. M., 1989. Saúde, nutrição e classes sociais: O nexo empírico evidenciado em um grande centro urbano, Brasil. Revista de Saú de Pública, 23:422-428.

MOYSÉS, M. A. A. \& LIMA, G. Z., 1983. Fracasso escolar, um fenômeno complexo: Desnutrição apenas mais um fator. Pediatria, 5:263-269.

NOVAES, M. H. D., 1979. A Puericultura em Questão. Dissertação de Mestrado, São Paulo: Faculdade de Medicina, Universidade de São Paulo.

ORLANDI, O. V., 1985. Teoria e Prática do Amor à Criança: Introdução à Pediatria Social no Brasil . Rio de Janeiro: Jorge Zahar Editor.

RIVOREDO, C. R. S. F., 1995. Cuidar eTratar de Crianças: Breve História de uma Prática. Taubaté: Cabral.

ROSEN, G., 1979. Da Polícia Médica à Medicina Social. Rio de Janeiro: Graal.

ROUSSEAU, J. J., 1992. Emílio ou da Educação. Rio de Janeiro: Bertrand Brasil.

SUCUPIRA, A. C. S. L., 1981. Relações Médico-Paciente nas Instituições de Saúde Brasileiras. Dissertação de Mestrado, São Paulo: Faculdade de Medicina, Universidade de São Paulo.

TANAKA, O. Y., 1982. Avaliação do Programa de Assi stência à Criança da Secretaria da SaúdedeSão Paulo. Dissertação de Mestrado, São Paulo: Faculdade de Saúde Pública, Universidade de São Paulo.

TANAKA, O. Y. \& ROSENBURG, C. P., 1990. Análise da utilização pela clientela de uma unidade ambulatorial da Secretaria da Saúde do Município de São Paulo, SP (Brasil). Revista de Saúde Pública, 24: 60-68. 